\title{
Research and Application Status of Envelope Structures for Fabricated Substations in China
}

\author{
Xueqing Sheng ${ }^{1 \varpi}$, Shengjun Pan ${ }^{1 \boxplus \square}$, Jiahui Chen ${ }^{1 \boxplus 0 \square}$ \\ ${ }^{1}$ Hangzhou Electric Power Design Institute Co.,Ltd.Hangzhou 132012,China;
}

\begin{abstract}
In recent years, Chinese prefabricated buildings have re-heated and showed rapid growth. This paper analyzes the performance of the existing assembled wall panels in the Chinese market by comparing the performance of different materials and optimizing the selection of the envelope structure of the assembled substation. Studies have shown that the use of prefabricated building systems can achieve the goal of shortening the construction period, reducing manual labor, no waste during construction, and no wet work on site.
\end{abstract}

\section{Introduction}

Since 2014, China has successively issued a number of important policy documents to promote the development of prefabricated buildings. The State Council issues the "Opinions on Promoting the Sustainable and Healthy Development of the Construction Industry" which requires by 2025, the proportion of prefabricated buildings in new buildings will reach $30 \%$. At the same time, prefabricated buildings have been widely used in industrial plants.

\section{Characteristics of the envelope structure of traditional substations}

The substation envelope structure generally adopts the on-site masonry construction method, and the material selection is mostly brick masonry. During the construction process, on-site procurement of sand and stone brick reinforced cement and other building materials was used. This kind of operation has uneven engineering quality due to the uneven technical level of the construction teams. At the same time, long period of construction which makes the on-site civilized management more difficult is common quality problem in traditional envelope structures. Moreover, the traditional surface decoration is generally sand rubbing or ordinary plastering, or a decorative coating layer, which will cause some common quality problems. For example, ordinary brick wall plastering is prone to plastering hollows, cracks, surface cracks, shedding, anti-alkali, fluff, etc. These common problems are difficult to overcome due to the difference in the quality of the floor materials used.

\section{Substation assembled wall}

\subsection{Common assembled wall structure}

In developed countries in Europe and the United States, due to higher labor cost, the construction of substations is less likely to use cast-in-situ concrete structures, but more steel structures and finished envelope structures (such as profiled steel plates) are used. The main structure of indoor substations in Japan generally uses clear water concrete technology, and the inner partition walls are assembled with finished wall panels produced by the factory.

Since the Economic Reform and Open Up in China, with the economic development, prefabricated buildings have been widely used in industrial plants. The light assembled substation actively explored by the National Electric Power Company is an important innovation that deeply implements the requirements of the State Grid Corporation's "two-type, one-ization" construction. And the prefabricated wall is a key link in implementing this policy.

\subsection{B. $R$ \& D significance of prefabricated wall panels}

With the economic development of the society, the scale of substation construction has gradually increased. The prefabricated wall panel can effectively shorten the construction period from the manufacturer's prefabrication to the crane site installation, and its construction period can be $40 \%$ ahead of time, which is conducive to site safe and civilized construction management. The internal quality and performance quality of the installation have met the requirements of

\footnotetext{
*:sxq_ks@163.com; **:496183759@qq.com;***:gyyomi@163.com
} 
the acceptance specification of the substation, avoiding the common quality problems of cracking or peeling of the brick wall plastering layer in the past. Production, standard and simplified prefabricated substation is one of the long-term development directions of substation construction.

\subsection{Advantages of prefabricated wallboard}

(1) Industrialized production: The project department proposes a production plan. And then according to the quality requirements of the project department and the schedule of the substation, the manufacturer products, processes and delivers prefabricated wallboard to the construction site.

(2) Easy and quick installation: Easy and quick installation of prefabricated wallboard effectively shortens the construction period, fully realizes the mechanized construction, reduces the workload of wet work on site and promotes the phenomenon of safe and civilized construction on site.

(3) Stable structural performance: Prefabricated wallboard adopts reinforced concrete column and slab structure, and its structural strength and anti-overturning performance are much larger than brick wall panels.

(4) Green environmental protection. Neat and beautiful appearance.

\section{Application status of prefabricated wallboard}

There are five main prefabricated wall boards: Auto lightweight concrete, glass fiber reinforced cement board, metal rock wool sandwich board, fiber reinforced cement board, and acrylic nitrile-styrene board.

\subsection{Auto lightweight concrete (ALC board)}

ALC board uses silica sand, cement, lime, etc. as the main raw materials and it is a new type of green environmental protection building material with good performance. It can be used as the internal and external wall envelope structure and roof board in industrial and civil buildings.

\subsection{Glass-fiber reinforced cement (GRC board)}

Glass-fiber reinforced cement is a new type of composite material, which is composed of cement, alkali-resistant glass fiber and water as main raw materials. Adding glass fiber to cement mortar can greatly improve its bending strength, tensile strength and impact strength. In addition, due to the flexibility of glass fiber and various methods of use, it has given glass fiber reinforced cement composites good process performance, making it more suitable for making various thin-walled products with complex shapes.
The common used GRC products mainly include GRC lightweight hollow partition boards and GRC composite exterior wall boards.

\subsection{Metal Rock Wool Sandwich Board (LCF board)}

The metal rock wool sandwich panel is made by bonding two laminated steel plates and the intermediate structure rock wool together with a special adhesive and then curing by pressure. The top and bottom or inside and outside panels of the rock wool sandwich boards are coated steel sheets, and the profiled steel sheets are formed by rolling and cold bending. The core layer is a non-combustible, hard, hydrophobic rock wool board or mineral wool board. Adhesive is used for bonding, and the fiber direction of the core layer is perpendicular to the panel. After the forming of the sandwich panel, the upper and lower floors of steel plates are integrated with rock wool and they work together. Therefore, it is a new type of multifunctional composite board.

It is widely applicable to a variety of large-scale industrial plants, roofing and wall envelope materials of public buildings, especially the outer envelope materials of commercial buildings and civil buildings that require high building facades.

\subsection{Fiber reinforced cement board (FC board)}

FC board is formed of wood pulp fiber, cement, sand, additives, water and other organic and inorganic substances after mixing, molding, pressing, high-temperature autoclaving and surface treatment. It is a type of lightweight board without asbestos and other harmful substances. And it can be molded into a variety of thicknesses and densities.

FC board inherits the advantages of waterproofing and anti corrosive of cement products, and overcomes the disadvantages of easy drying and shrinkage of cement products. It also increased strength. Therefore, FC board is a stable, environmentally friendly and high-strength material.

\subsection{Acrylonitrile-styrene board (AS board)}

AS prefabricated wallboard is an integral part of prefabricated building system. This complete system is the research results of Waseda University, Japan and has more than 60 years of development and practice. It is divided into external wall system and interior finished wall system. The whole system includes wall materials, functional materials, link materials and closed materials.

AS board belongs to silicate concrete products. The main materials are cement, silica, polyester fiber, pulp fiber, and additives.

Here are the figures of ALC board, GRC board, LCF board, FC board, AS board from Figure 1 to Figure 6 . 


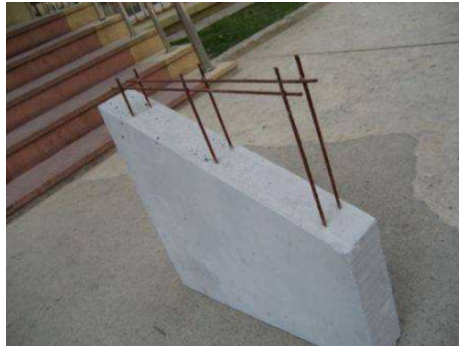

Figure 1: ALC board

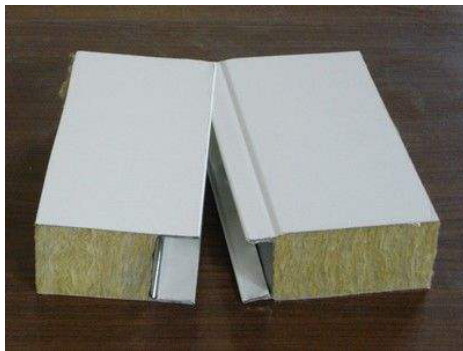

Figure 4: LCF board

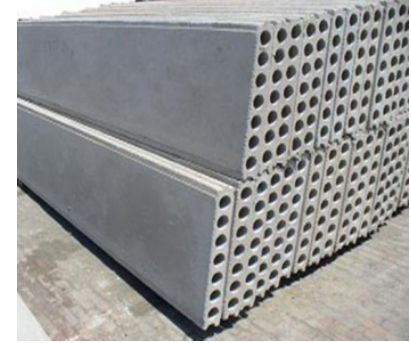

Figure 2: GRC lightweight hollow partition wallboard

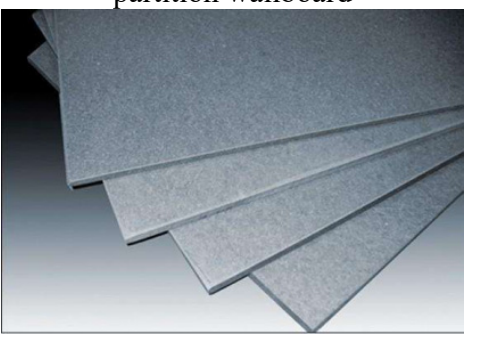

Figure 5: FC board

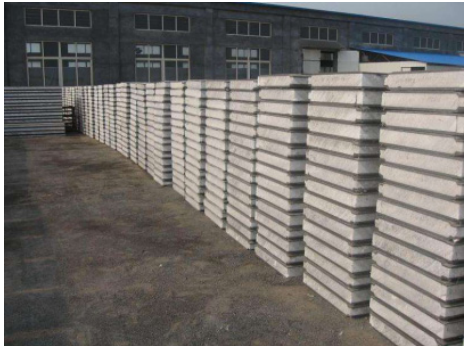

Figure 3: GRC composite exterior wallboard

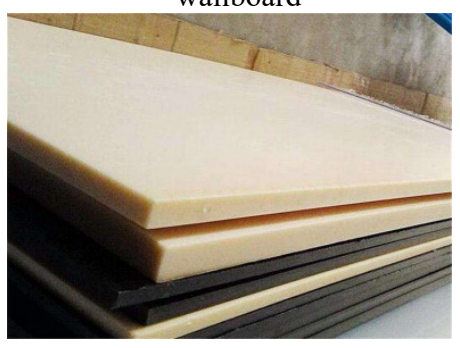

Figure 6: AS board

\section{Material performance comparison}

Here is the comparison of mechanical and physical properties. As is shown in Table 1.

Table 1: Comparison of mechanical and physical properties

\begin{tabular}{|c|c|}
\hline SPECIES & MECHANICAL AND PHYSICAL PROPERTIES \\
\hline ALC board & $\begin{array}{l}\text { Lightweight and high-strength, with good durability, sound insulation and sound } \\
\text { absorption, slightly abrasion resistance }\end{array}$ \\
\hline LCF board & $\begin{array}{l}\text { Light weight, high strength, high toughness, high weather resistance, poor water } \\
\text { resistance } \\
\text { High shear strength and certain toughness, the strength is not good enough, and the } \\
\text { waterproof performance is poor }\end{array}$ \\
\hline AS board & $\begin{array}{l}\text { Lightweight and high strength, good environmental protection, good waterproof and } \\
\text { moistureproof performance }\end{array}$ \\
\hline & $\begin{array}{l}\text { Has a strong ability to withstand loads, resistance to chemical reactions, thermal } \\
\text { deformation resistance and geometric stability, high durability, and strong resistance } \\
\text { to freeze-thaw }\end{array}$ \\
\hline
\end{tabular}

The following are the specific values of the physical properties of the five types of boards, and they are shown from Table 2 to Table 6.

Table 2: Various physical properties of ALC board

\begin{tabular}{cc}
\hline Physical properties & Value \\
\hline & 650 \\
Mass per unit volume $(\mathrm{kg} / \mathrm{m})$ & $>3$ \\
Compressive strength $\left(\mathrm{N} / \mathrm{mm}^{2}\right)$ & $0.78-1.18$ \\
Bending strength $\left(\mathrm{N} / \mathrm{mm}^{2}\right)$ & $0.39-0.88$ \\
Shear strength $\left(\mathrm{N} / \mathrm{mm}^{2}\right)$ & $0.39-0.59$
\end{tabular}

Table 3: Various physical properties of GRC board

\begin{tabular}{cc}
\hline Physical properties & Value \\
\hline Flexural strength(Mpa) & $>18$ \\
Compressive strength(Mpa) & $>40$ \\
\hline
\end{tabular}


Table 4: Various physical properties of LCF board

\begin{tabular}{|c|c|}
\hline Physical properties & Value \\
\hline Tensile strength $\left(\mathrm{kgf} / \mathrm{m}^{2}\right)$ & average value $>0.1$ \\
\hline Compressive strength $\left(\mathrm{kgf} / \mathrm{m}^{2}\right)$ & 1.5 \\
\hline \multicolumn{2}{|c|}{ Table 5: Various physical properties of FC board } \\
\hline Physical properties & Value \\
\hline Flexural strength $\left(\mathrm{kg} / \mathrm{cm}^{2}\right)$ & $\leq 300$ \\
\hline Anti-fold strength(Mpa) & $15-20$ \\
\hline \multicolumn{2}{|c|}{ Table 6: Various physical properties of AS board } \\
\hline Physical properties & Value \\
\hline $\operatorname{Proportion}\left(\mathrm{g} / \mathrm{cm}^{3}\right)$ & 1.05 \\
\hline Compressive strength(Mpa) & 14 \\
\hline
\end{tabular}

Table 7 to Table 9 are the comparison of thermal performance and the comparison of economic insulation performance, the comparison of fire performance.

Table 7: Comparison of thermal insulation performance

\begin{tabular}{|c|c|c|}
\hline Species & Insulation performance & Heat transfer coefficient $\left(\mathrm{W} / \mathrm{m}^{2} \cdot \mathrm{k}\right)$ \\
\hline ALC board & $\begin{array}{l}10 \text { times than the thermal insulation } \\
\text { properties of ordinary concrete }\end{array}$ & $0.75(200 \mathrm{~mm}$ board thickness $)$ \\
\hline & Good thermal insulation performance & $0.9(200 \mathrm{~mm}$ board thickness $)$ \\
\hline GRC board & Good thermal insulation performance & $0.588(200 \mathrm{~mm}$ board thickness $)$ \\
\hline LCF board & $\begin{array}{l}\text { Good thermal insulation performance } \\
\text { and good thermal insulation }\end{array}$ & $\begin{array}{c}0.955(215 \mathrm{~mm} \text { plate thickness exterior } \\
\text { wall })\end{array}$ \\
\hline FC board & performance & $0.596(215 \mathrm{~mm}$ thick wall $)$ \\
\hline AS board & $\begin{array}{l}\text { General thermal insulation } \\
\text { performance }\end{array}$ & 2.22 \\
\hline
\end{tabular}

Table 8: Comparison of fire performance

\begin{tabular}{cc}
\hline Species & Fire performance \\
\hline ALC board & $\begin{array}{c}\text { Non-combustible, high fire resistanc } \\
\text { Come with fire insulation }\end{array}$ \\
GRC board & LCF core material is \\
LCF board & non-combustible material \\
FC board & Good fire resistance, \\
& non-combustible
\end{tabular}

AS board Good fire performance

Comparing the performance of the above five wallboard materials, it can be seen that the AS boards have better performance in all aspects, and its fire resistance is better than ALC boards under the same conditions. ALC boards have better performance in all aspects, but poor wear resistance. Compared with AS assembled wall boards, ALC boards are more of a

\section{Fire resistance $(\mathrm{h})$ \\ 3.2(100 mm thick ALC board) \\ 2 \\ Fire resistance in line with national standards \\ 4.5(100 mm thick AS fabricated wall panels)}

substitute for traditional building envelopes. The disadvantages are low strength and non-decorative nature, and secondary decoration of external surfaces is required. After the completion of the prefabricated building, the interior appearance is not much different from that of a conventional building.

Table 9: Comparison of economic performance

\begin{tabular}{ccc}
\hline Species & Price $\left(¥ / \mathrm{m}^{2}\right)$ & Installation and maintenance \\
\hline ALC board & $<700$ & Cheap price with high maintenance \\
cost
\end{tabular}



AS board
costs

Note: The prices in the table are comprehensive prices, including internal support such as keel and labor costs.

Comparing the economic performance of the above five types of wallboard materials, it can be seen that the price of LCF boards is more expensive, so LCF boards are not a economical enough choice. AS boards, ALC boards and GRC boards are lower in price, and they are more suitable for industrial buildings such as substations that do not require particularly high facades. The ALC boards, FC boards, and GRC boards do not have a decorative surface. They need to be re-decorated on the spot. So there are certain maintenance costs later.

\section{Conclusion}

With the economic development of society, the envelope structure of prefabricated buildings becomes more and more important in the substation construction. This structure makes a full consideration of the material performance and economic indicators. And it can effectively shorten the construction period, reduce costs, and implement the new concept of green building.

\section{Acknowledgments}

The authors gratefully thank Zhejiang Electric Power Corporation for providing the technical support. This work was supported by Research and Application of Key Technologies for Modular Construction of Fabricated Substation(SGTYHT/18-JS-202).

\section{Reference}

1. Kazem H, Bunn W G, Seliem H M, et al. Durability and Long Term Behavior of FRP/Foam Shear Transfer Mechanism for Concrete Sandwich Panels[J]. Construction and Building Materials, 2015, 98:722-734.

2. JCI.Method of Test for Flexural Strength and Flexural Toughness of Fiber Reinforced Concrete:JSCE-SF 4[S]. Tokyo:Japan Concrete Institute, 1984.

3. Felicetti R, Gambarova P G, Bamonte P. Thermal and Mechanical Properties of Light-Weight Concrete Exposed to High Temperature[J]. Fire and Materials, 2013, 37(3):200-216.

4. $\mathrm{Ng} \mathrm{S} \mathrm{C,} \mathrm{Low} \mathrm{K} \mathrm{S,} \mathrm{Tioh} \mathrm{N} \mathrm{H.} \mathrm{Thermal} \mathrm{Inertia} \mathrm{of}$ Newspaper Sandwiched Aerated Lightweight Concrete Wall Panels: Experimental Study[J]. Energy and Building, 2011, 43(10):2956-2960.

5. Oka H, Yamada S, Lgarashi S, et al. Stiffness and Strength of ALC Core Sandwich Slabs Adhesively Bonded with Steel Skins[J]. Journal of Structural and Construction Engineering, 2011, 76(2): 427-435. 